\title{
ADAPTATION THROUGH WATERSHED MANAGEMENT IN THE CHANGING CLIMATE
}

\section{KHAN MTR* \\ OMPRAKASH M.D.}

Received: 24/02/2014

Accepted: 28/11/2015

Available online: $15 / 12 / 2015$
Indian Institute of Forest Management, Bhopal, India

*to whom all correspondence should be addressed: e-mail:trkres@gmail.com

\section{ABSTRACT}

Civilization has been experiencing frequent changes in the climate due to global warming. The developing nations are worst affected as they are largely dependent on the local precipitation and soil moisture for their livelihood generations. The changing climate with extended summer, change in the rainfall pattern (intensity and duration) and variations of onset and departure of seasons are directly impacting the cultivation, status of natural vegetation, surface and sub-surface water, and other natural resources in a watershed area. Among the various efforts, watershed development approach, in which intervention is more site-specific in nature and can address the local requirements, is found to be more effective at micro levels. The vulnerability of climatic changes is mainly due to water stress, degradation of natural vegetations, degradation in the health and hygiene conditions, and poor information communication technology. The present article highlights these issues, impact of watershed development project in the Himalayan region and identifying the adaptation mechanism through watershed programs. A site specific action, research methods including primary and secondary data collections, GIS, remote sensing and statistical techniques were used. The study on the Jusho Bakro micro-watershed treated by TERI under the program DROP has been found to be effective in drawing possible adapting mechanism to withstand the changing climate and its severity on the natural resources and the livelihood of the community.

Keywords:Climate change, adaptation, ecosystem, forest, GIS and remote sensing

\section{Introduction}

"Warming of the climate system is unequivocal, as is now evident from the observations of increases in global average air and ocean temperatures, widespread melting of snow and ice, and rising global mean sea level". This is a major conclusion drawn in the fourth Assessment Report of Working Group I (WGI) of the Intergovernmental Panel on Climate Change (IPCC) (IPCC, 2007). The updated 100-year linear trend (1906-2005) of $0.74{ }^{\circ} \mathrm{C}$ is more prominent than the corresponding trend of $0.6^{\circ} \mathrm{C}$ for $1901-2000$ of the Third Assessment Report (TAR), 2001. According to the report, observed increase in globally averaged temperatures since the mid-20th century was likely due to the increase in anthropogenic greenhouse gas (GHG) concentrations. The Report further emphasised that continued GHG emissions at or above the current rates would cause further warming and induce many changes in the global climate system during the 21st century; this would likely be larger than those observed in the 20th century. Advancement in climate change modelling has improved the estimates of future change and its associated uncertainty ranges for different emission scenarios. The increase in temperature for the low emission scenario (B1) is $1.8^{\circ} \mathrm{C}$ (likely range is $1.1{ }^{\circ} \mathrm{C}$ to $2.9^{\circ} \mathrm{C}$ ), and the increase in temperature for the high emission scenario 
(A1FI) is $4.0^{\circ} \mathrm{C}$ (likely range is $2.4{ }^{\circ} \mathrm{C}$ to $6.4{ }^{\circ} \mathrm{C}$ ). These projections are broadly consistent with the span quoted in the TAR, however they are not directly comparable (IPCC, 2007).

Depending on the emission scenario, model-based projections of global average sea level rise at the end of 21st century (2090-2099) are also found to be variable. For example, for the B1 scenario, sea level rise is projected to be $0.18-0.38 \mathrm{~m}$, where as for the A1FI scenario, it could be $0.26-0.59 \mathrm{~m}$. It can be noted that the model-based range excludes future rapid dynamical changes in ice flow. The ranges are narrower than in the TAR (0.13-0.88 $\mathrm{m}$ ), which is mainly because of improved information about some uncertainties in the projected contributions. The warming due to anthropogenic influence and consequent sea level rise would continue for centuries due to the timescales associated with climate processes and feedbacks, even if greenhouse gas concentrations were to be stabilized.

The most useful index describing the state of global climate is the average surface air temperature of the planet. Records show that global temperature has risen by about $0.6{ }^{\circ} \mathrm{C}$ since the beginning of the twentieth century, with about $0.4{ }^{\circ} \mathrm{C}$ of this warming occurring since the 1970s. The year 1998 was the warmest in this 142-year record, and 2001 was the third warmest. Globally, the decade of the 1990s was the warmest in the last 100 years, and it is likely the last 100 years was the warmest century in the last millennium. During the past century, other evidences for changes in global climate have emerged as the night-time temperatures have increased over many land areas at about twice the rate of day-time temperatures, growing seasons have lengthened, more intense rainfall events observed over many $\mathrm{mid} / \mathrm{high}$ latitude land areas, a near worldwide decrease in the size of mountain glaciers, and Northern Hemisphere sea-ice has decreased and there has been a substantial thinning of Arctic sea-ice in late summer.

In general, we expect climate change, through increasing temperatures, to cause a northward shift in the major biomes (broad ecosystem types) of the world. This will involve a northward expansion of the tropical belt and a northward expansion of the boreal forest and tundra regions. In addition, rising temperatures result in increased evaporation of water from the land-surface and plants; this coupled with decreases in precipitation in some regions will lead to a shift towards drier biomes. So tropical rain forests are likely to shrink, for example, and many plants and animals unable to adapt to such rapid changes in climate could become extinct. Of course the climate has changed in the past - and plant and animal species have simply shifted geographically over a period of time, tracking the changing climate. The problem in the next decades will be greatly exacerbated by both the rate of change and by the fact that many plants and animals will find man-made barriers, such as cities or agricultural areas, physically blocking migration as the climate changes. The indirect impacts of climate change could include disruption of economies and political instability. The impacts of climate change depend, in part, on the vulnerability and ability to adapt of different communities and sectors. It is likely that those who have least resources - economic, infrastructural or social (e.g. networks of support through strong communities), especially the developing countries including India - will be most greatly affected.

Climate change together with other socio-stresses (e.g., population growth, urban expansion, economic growth, globalization, etc.) will have substantial impact on water resources in terms of scarcity (drought) and abundance (flooding). The South Asian region, including India, has been historically vulnerable to climatic extremes and it is very likely that the vulnerability will increase in the future due to climate change. Coping capacity of most of the population is limited due to poverty, low per capita income, and lack of access to social capital and administrative and political disconnected functionalities. Vulnerability of population from extreme hydro-meteorological hazards can be reduced through adaptive governance, which includes climate focused development, mainstreaming adaptation in development planning, institutional and political reforms and international cooperation. Climate variability and change add to vulnerability, in particular of the poor. With climate change being on its way, even if serious mitigation measures are implemented soon, there will be a need for adapting to the effects, such as higher average temperatures, further aridification of already dry regions and more extreme and frequent floods and droughts. 


\section{Adaptation}

Climate change in relation to the economic, social and ecological aspects has been studied in detail at the large scale. However studies on the micro level interventions or measures, which are the primary needs to ensure that the poor are not affected/ punished for being ignorant/ innocent, are still in infancy. Climate change researchers and policymakers are increasingly focusing on adapting to a changing climate, but they have not yet spelled out how to do so with ground-level action. Working from different points of departure, both disciplines have come to a common conclusion that natural resource mismanagement contributes to the vulnerability of human systems to hazards caused by the changing environment, and enhanced management can provide a tool for vulnerability reduction. Adaptation refers to change in a system in response to some force or perturbation such as climate change (Smithers and Smit, 1997; Smit et al., 2000). History gives us the witnesses that, people have been adapting to the changing conditions, but what is needed is to incorporate future climate risks into policy making (Lim et al., 2005). It also gives us an opportunity to revisit some of the unresolved disaster reduction and sustainable development issues (Subbiah, 2002). Adaptation is important in climate change in two ways - in reducing the impacts of the future climate change and in understanding the options for such adaptations to climate changes. There is a need for accelerating the planning and adaptation due to the fact that the accelerated human induced changes in the climate may outpace the natural adaptation capabilities built in the existing systems (Bruce et al., 1996). Experience from around the world shows that adaptation also prepares to some degree for future climate change, and can at the same time help to achieve development goals. However large part of the human population may be facing considerably higher climate risk in the future, for which the current coping mechanisms alone are no longer sufficient. When a watershed reaches the limit of its coping capacity, people are not prepared to cope with any more severe water scarcity or more intense droughts.

The most effective contribution of climate change adaptation lies in providing countries with tools and information for adapting their agriculture, fisheries and forestry policies and practices to changing climate regimes and to improve farmers' capacities to reduce risk or make optimal use of climate variability. This includes: agro-meteorological data and tools for assessing the impact of extreme weather and for guiding adaptation; improving management advice to farmers on the basis of current weather monitoring (contingency planning and response farming); vulnerability assessment tools; guidance on rural livelihood development related to decision making by farmers, herders and fishermen; promoting integrated approaches and synergies between climate change adaptation and disaster risk reduction practices and mechanisms in agricultural sectors; policy advice to strengthen institutional approaches to disaster risk reduction and climate change adaptation from a sectorial perspective; promoting sustainable natural resource management as basis of adaptation to climate variability and change; and improving householdlevel food security to help rural populations achieve greater resilience under short-term and mediumterm climate variations(http://www.fao.org). The conventional approaches require more manpower in turn burgeoning expenditure of the project. The modern techniques like remote sensing and GIS found to be cost effective as well as able to provide accurate and temporally variable information.

Several actions promoting adaptation include integration of climate information into environmental data sets, vulnerability or hazard assessments, broad development strategies, macro policies, sector policies, institutional or organizational structures, or in development project design and implementation (Burton and van Aalst, 1999; Huq et al., 2003). It is argued that with the implementation of mainstreaming initiatives, adaptation to climate change will become part of or will be consistent with other well established development programs, particularly sustainable development planning (Adger et al., 2007).

Though many measures are being taken up to combat and overcome these problems through large scale interventions at global level, such as the carbon trading mechanisms evolved in the Kyoto protocol, these problems persist and the real sufferers are the poor and the people who are dependent on natural resources for their livelihood. For instance, climate change affects the frequency and magnitude of floods and droughts which further affect agriculture, cattle and farmers and other vulnerable water sectors. The systems evolved in the Kyoto and other UNFCC Conventions have tried to address the problem of 
increasing GHGs at the global level favouring the rich and the polluters, and hence ignoring the rural and poor people.

As a perspective on strategies to deal with climate change, India's National Action Plan on Climate Change (NAPCC) 2008 enumerates several policy measures that the government intends to take for adaptation. It also recognizes climate sensitive sectors within the economy and lists activities that are already being taken up to minimize the impact of climate change such as crop improvement, drought proofing, forestry, water, coastal regions, health, risk financing and disaster management. Though India has taken a number of steps to bridge the gap in development, there are still requirements to fill the gaps of huge developmental backlogs in the fast growing nation. The recent focus on adaptation to climate change has re-emphasized the existing deficits in various development sectors and deficits that are prone to increase due to the adverse impacts of climate change. Moreover, the climate change is likely to wear down developmental gains and make the existing developmental initiatives more expensive. It is sensible to realise that efficiency of adaptation policies and its cost-effectiveness will largely depend on the country embracing a sustainable growth and development course (Ganguly K. and Ranjan G., 2010).Effective adaptation means the establishment of adaptive capacity (awareness, governance, and knowledge) as well as the adaptation itself (change of behaviour, practices, and livelihoods according to new conditions) (Mirza, 2007). Its focus should incorporate enhanced capacity to adopt (implying a comprehensive approach) new adaptation strategies. "An adaptation strategy to reduce vulnerability to future climate change needs to be incorporated in regulatory procedures, integrated natural resources management and other development planning procedures" (UNDP-GEF, 2007). As poverty and gender indiscrimination are widespread in the Indian region, the empowerment of poor people and the women to adapt to climate change is important.

In the Indian context, the watershed conservation and management in recent years has become very popular, together with various interventions for sustainable natural resource management and rural development in general. Development agencies have made a move from "delivery model" towards participatory progression. The watershed development programmes have evolved from just confining to hydrological and ecological development. Programmes now add economic and social aspects as an integral component and hence moving towards a people-centred approach. Therefore such approach shall be an effective tool to combat the effects of climate change by bringing in economic, ecological and social development among the rural poor. The application of GIS and remote sensing techniques will be helpful in the context of better understanding of the changing scenarios, measures to combat the impacts, planning and management purposes and for further research openings.

\section{Study Area}

The present study area, Jusho Bakro Micro-watershed is in Kalsi block, Dehradun. The micro watershed (MWS) is the part of Samalta Gad watershed and Amala Gad sub-basin of the upper Yamuna basin. Total area of the MWS is about 260 ha that extends between longitude $77^{\circ} 54^{\prime} 10.10^{\prime \prime} \mathrm{E}$ to $77^{\circ} 55^{\prime} 33.22^{\prime \prime} \mathrm{E}$ and $30^{\circ} 36^{\prime} 19.18^{\prime \prime} \mathrm{N}$ to $30^{\circ} 37^{\prime} 30.24^{\prime \prime} \mathrm{N}$. The area falls in the Survey of India (SOI) topo sheet 53F/14. The area is located at a distance of $18 \mathrm{~km}$ away from Kalsi. The approach road of $8 \mathrm{~km}$ connects the project villages from the road between Chakrata and Kalsi. For the purpose of resource assessment a detail study has been conducted in the villages, Jusho Bakro, Samalta, Dudli, Ichala and Bamrad. This is shown in Fig. 1. Out of these 5 villages four are revenue villages of Kalsi block, where as Dudli village falls under Samalta revenue village. These villages are degraded due to poor natural vegetation and heavy runoff from the catchments. The Panchayats of these revenue villages are Samalta, Udpalta, Bamrad and Damta. These villages are in one cluster and situated in the discharge zones of the micro-watershed, and thus any activities done in the ridges will impact them.

There has been a discernible change in the climate of the study area in the recent decades. The main trends indicate a decrease in precipitation especially over higher altitudes, and change in the precipitation temporal pattern, warming leading to milder winters, warmer springs and the recession of glaciers. These villages are degraded due to poor natural vegetation and heavy runoff from the catchments. Moreover, 
the community living in these villages are socially and economically deprived and backward. The location, watershed degradation and ongoing project make the proposed study area as an ideal site for applying the research questions and understand the impact of climate change on natural resources as well as on the economy of the people so as to suggest a suitable measure in watershed programmes to adapt to the impacts and reduce the severity of climate change/variations.

As studied from the data collected at Chakrata observatory, which is close to the study area during 1989 to 2007, the average annual rainfall is calculated to be $1189 \mathrm{~mm}$. The least rainfall was recorded in the year 1991 with $504 \mathrm{~mm}$ and 545 in the year 2003. Maximum rainfall was recorded in the year 1990, 2000 and 2007 with 1507, 1554 and $1975 \mathrm{~mm}$ respectively. This variation in the annual rainfall pattern indicates the frequent variations/changing climate in the study area. Fig. 2a also reveals the rainfall temporal pattern during the respective years. Major portion of the rainfall occurs during July to September due to South-West monsoon. Some amount of rainfall also takes place during the winter months in the region (Fig. 2b). This causes a kind of havoc in the people due to cultivation failure etc.

\section{Methodology}

The study has been divided into reconnaissance survey followed by setting of optimum sample, data collection from secondary and primary sources. The Questionnaire is developed on the basis of trial done in the field reconnaissance. Five villages are selected purposefully and they are on the basis of field conditions, project villages, and their locations with respect to the watershed geometry, and socioeconomic conditions. The collected data from the secondary and primary sources are compiled and data base is created. The experimental design has been adopted to understand the impact of watershed management approach on climate change. The social mapping and resource mapping in the area is done together with the villagers aiming to improve the understanding of the present scenario and detect the regional stakeholders. Various field based data collection methods, GIS and remote sensing techniques, and statistical tools (i.e. SPSS) to analyse, interpret and draw inferences have been used in the study. DROP (Development, Rehabilitation and Outreach Project) history methods from The Energy and Resources Institute (TERI) are also used to get an idea about conditions of the watersheds in the past and the present conditions. Available data consist of economic, social and ecological parameters collected from the field, and data about the climate and its variability. The secondary data has been validated through primary data of the social, economic and ecological parameters.
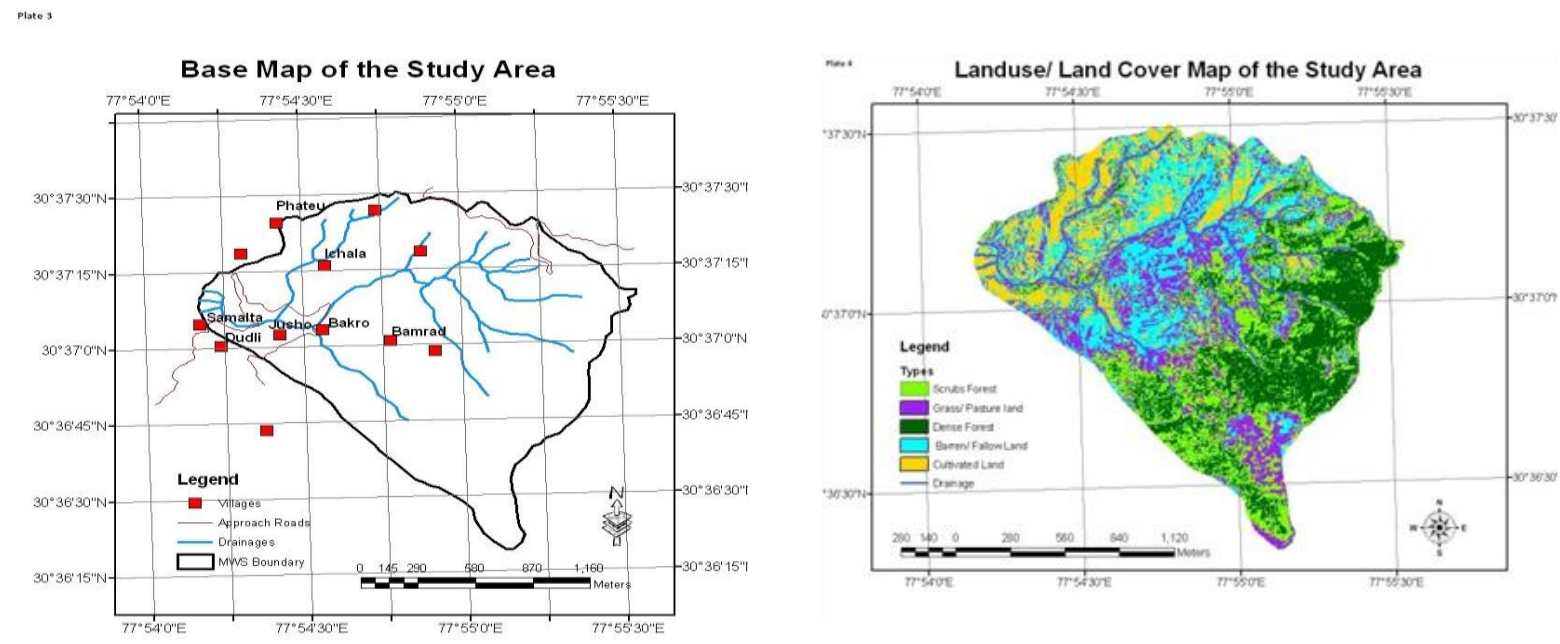

Figure 1. a) Base map of the study area, and b) land use / land cover map 

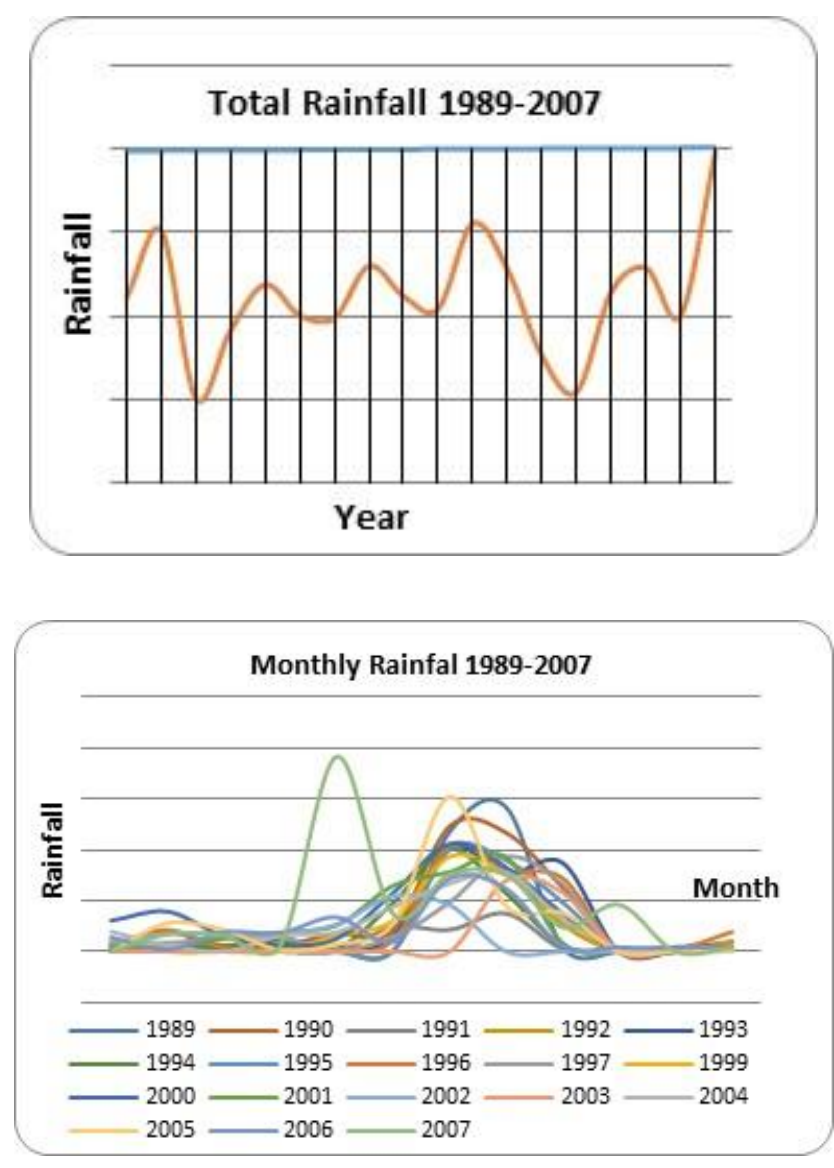

Figure 2. a) Annual and b) monthly variability of rainfall

(source: based on the data collected from the Chakrata Tehsil, Chakrata Forest, Dehradun) Note: Data for year 1998 were unavailable and thus it is excluded in the graph

\section{Results and Discussion}

\subsection{Activities to improve livelihood}

Since the initiation of the project, significant progress has been made towards the betterment of the people in the micro-watershed area.

Various activities have been undertaken in phases which have been well planned and executed such as soil and water conservation, water harvesting, irrigation and drinking water management. These activities are well defined in the strategies of climate change adaptation. The structures made in the area are site specific in nature and helped in addressing the local terms and collect water for irrigating the land as well as for 'Nistar' purpose (Nistar means the concession granted for the removal from forest coupes on payment at stipulated rates, specified forest produce for bonafide domestic use, but not for barter or sale; www.mahaforest.nic.in/internal.php?id=30/i).

The various activities in line with climate change adaptation also include the introduction of high yielding varieties and modern agricultural techniques, health and sanitation improvement activities, capacity building and community mobilisation, improved cook stoves, solar lighting devices, parabolic solar cookers and water mills, forestry activities such as afforestation, nursery establishment, and formation of forest protection committee, enterprise development including poultry production, mushroom cultivation, paper plate making and aromatic and medicinal plants cultivation, and ICT (information and communication technology). These activities are parts of the different strategies taken up for combating 
climate change and its impacts as an adaptation policy and strategic means to face the severity of the changing climate and its effects.

\subsection{Impact on drinking water}

There is an increased availability of clean drinking water due to construction of bawris (deep step wells) and distribution of low cost water filters as well as chlorination. These structures have the ability to harvest about $60 \%$ of the runoff from the catchment. There is an increase in irrigated land up to $17 \%$ in the study area, which is substantially increased looking to the period of the project implementation (Fig 3).

\section{Change in Irrigation Status}

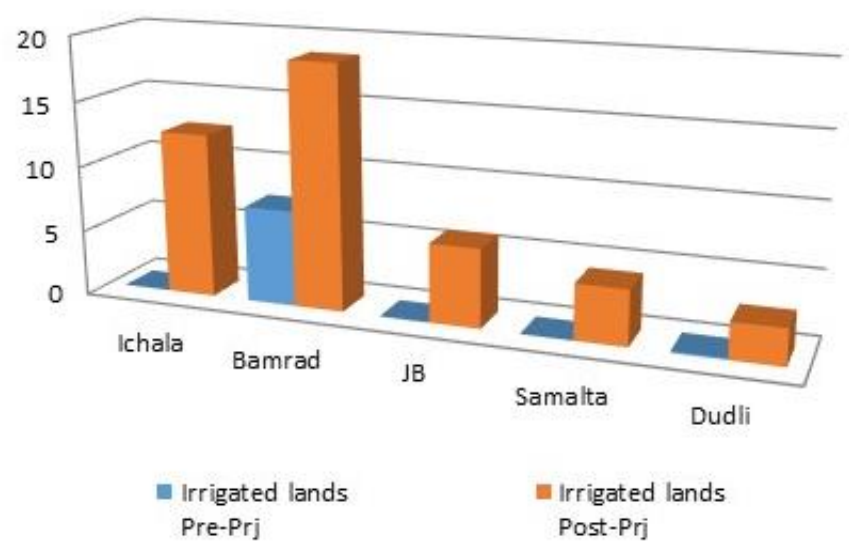

Figure 3. Graph showing the change in irrigation status

The increase in irrigated area enhanced gross cropped area and also livelihood of the people. However the exact amount of water stored before the structure can only be quantified after the observation such as water level and number of times water overflows from the structure in a year. People also opined that drinking water availability has increased. The ponds constructed or renovated remarkably reduced the shortage of drinking water in the villages. $100 \%$ of the respondents in all the villages gave the opinion that $10-15 \%$ of the drinking water availability has increased (Fig 4).

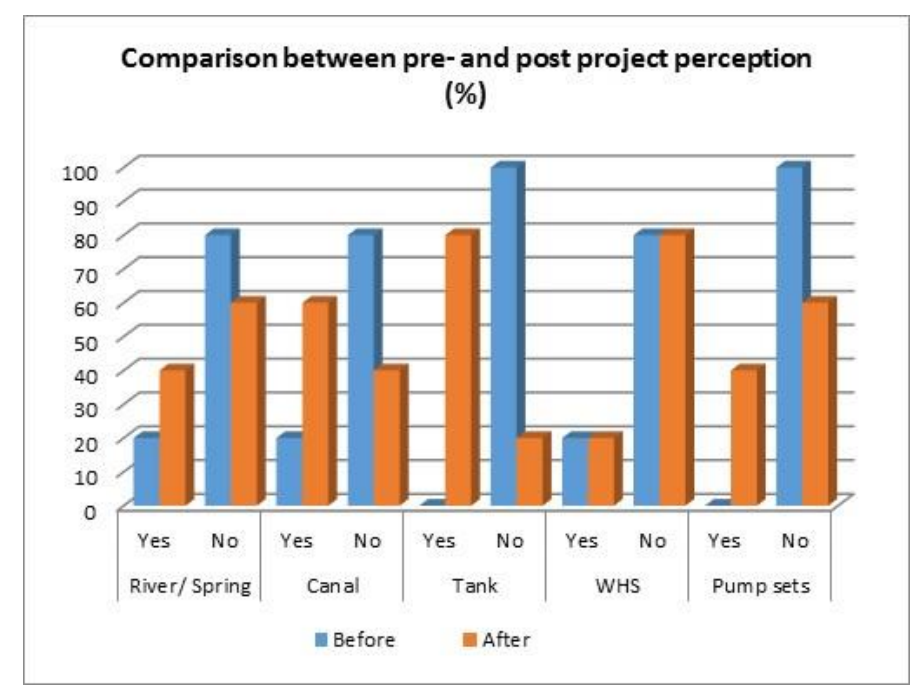

Figure 4. Graph showing people's perception on irrigation sources - comparison between pre- and post project scenarios 
These impacts produced a positive result in the adaptive capacity of villagers in the study area. But it is still in deficit looking to the ever increasing demand and degradation in the catchment area. Though the project could help the community in harvesting water and bringing it to their household, the increasing pressure on natural vegetation and ever increased demand may deficit the water availability in the future, especially during dry years. There is no scope in enhancing the landholding; however there is enough scope in the development of CPR (Common Property Resources) which is abundant. There is an observation as per the remotely sensed data that the land reported is less than the actual cultivated land. This might be due to encroachment for cultivation.

\subsection{Impact on agriculture and forestry}

Agriculture is becoming more productive with improved inputs and practices. Farmers are practising, along with the introduction of new scientific tools, new composting techniques, integrated pest management, improved seeds and micro irrigation systems as revealed in Fig. 5 indicating a sharp increase in the use of modern agricultural tools and techniques with a dramatic increase in the area of both the Rabi and Kharif crops as in Fig. 6 and Fig. 7 respectively.

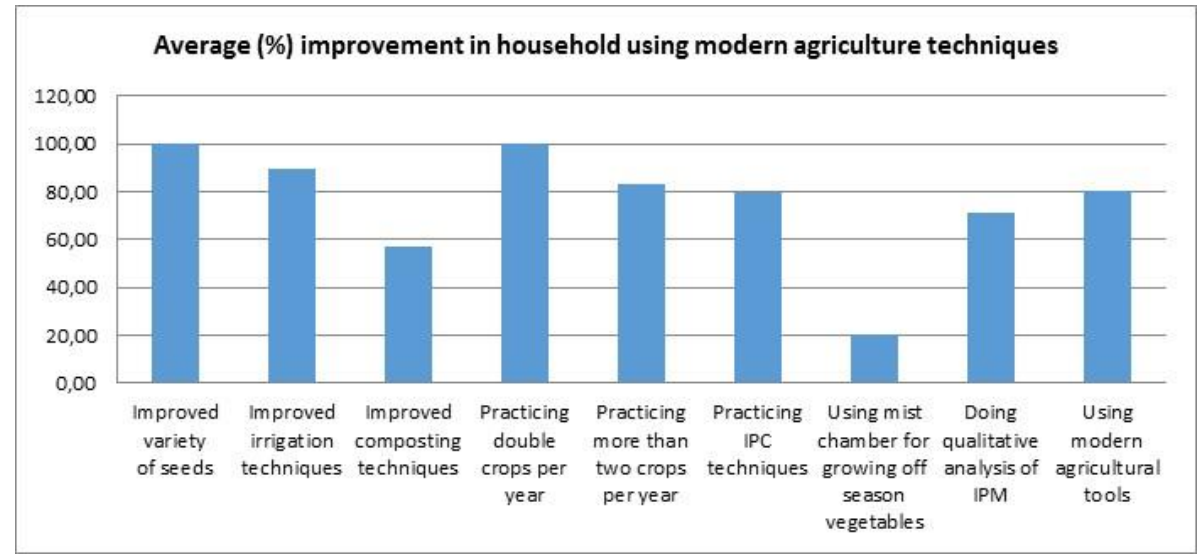

Figure 5. Graph showing the average (\%) improvement in households in using modern agricultural tools

There is a sharp rise in vegetable cultivation in the area such as tomato, beans, raddish, onion, coriander and brinjal (Fig. 8), while there is a decrease in the area of paddy cultivation in all the villages except in one village (Fig. 7). However, paddy (dhan) production increases as in Fig. 10 except in a village, which may be due to multiple factors such as increase in irrigation, water availability due to increase in irrigation facility, use of modern scientific tools such as high yielding variety etc.

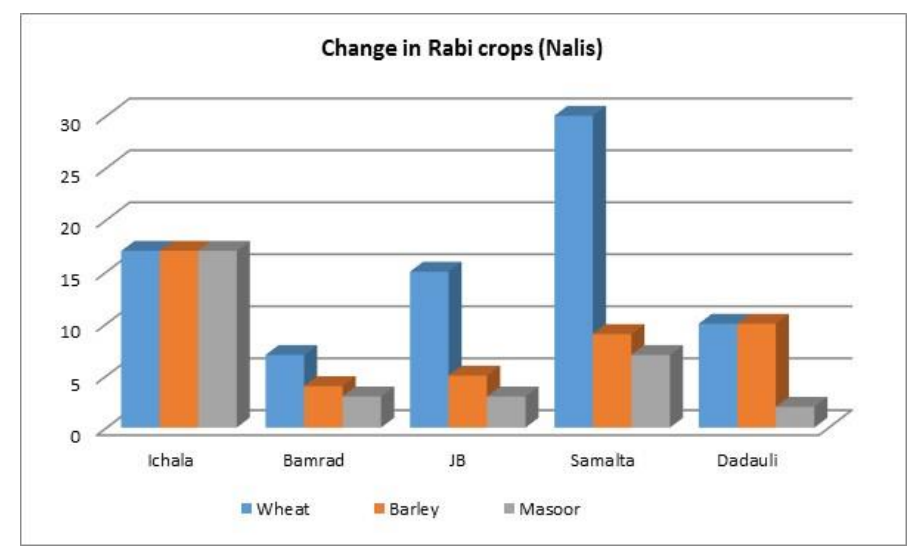

Figure 6. Graph showing the change in area of Rabi crops 


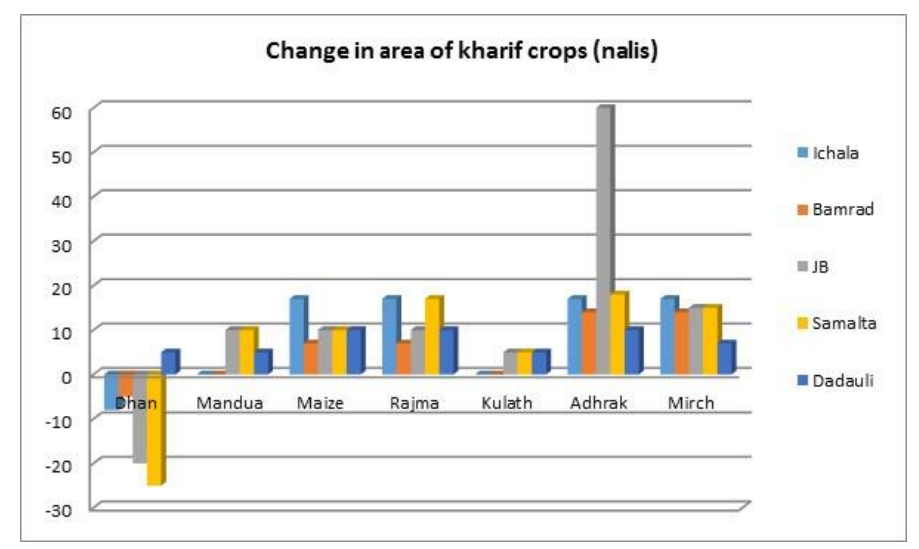

Figure 7. Graph showing the change in area of Kharif crops

Fig. 11 reveals that there is a dramatic increase in the yields of vegetables in all the study areas, with a sharp increase in tomato production as being the highest followed by the production of raddish, capsicum (including Simla mirch) and beans in a dramatic manner. Moreover, productions of okara, brinjal, coriander and onion also increased in the area. There is a dramatic rise in the yields of Rabi crops in all the villages as revealed in Fig. 9 as well as in the yields of Kharif crops as revealed in Fig. 10. It is a very interesting to observe a sharp increase in Kharif crops such as ginger (adhrak) production followed by the productions of chilli (mirch), paddy, maize, ginger and millet (mandua) as in Fig. 10.

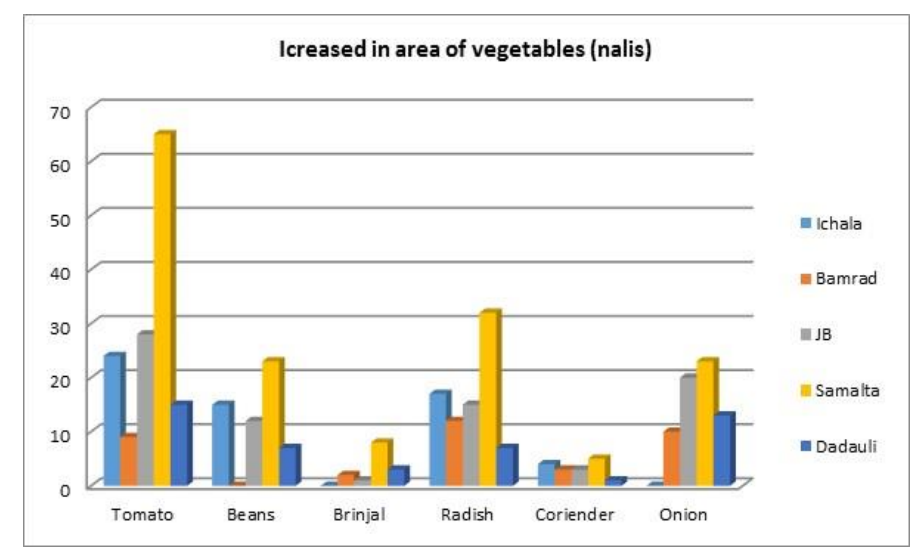

Figure 8. Graph showing the increased in area of vegetable cultivation

From the above discussions, it is clear that there is shift in crop pattern with more inclinations towards vegetable crops. This may be due to the introductions of modern technological tools, improved varieties, increased water availability with slightly increasing irrigation facility and better management practices adopted by the farmers due to the ongoing project activities in the study area. Farmers shift towards vegetable crops with high yielding varieties may be ascribed to the potential high productions of these crops with comparatively much higher market value. During the researcher's interactions with the farmers in the villages, they ascribed the reason for such a shift to the higher economic values of the vegetable crops. They said that tomato, ginger, raddish, capsicum and beans brought them higher profits in the market. Cultivation of ginger was becoming very popular due to its high market price outside the state. Shift in cropping pattern is seen in the area since the cultivators are intensifying cash crop production taking the advantage of the improved farming techniques. Cropping pattern in the villages has changed a lot. This is due to the introduction of cash crops such as vegetables, improved and high yielding varieties over the traditional crops such as paddy. Cultivation technique is another aspect that has changed from labour intensive to the use of bullock operated multipurpose plough. Agriculture is becoming more productive with improved inputs and practices (Fig 5-11). This has increased the demand of marketing the 
agricultural production since the inception of the project, thus directly adding opportunities for food and livelihood.

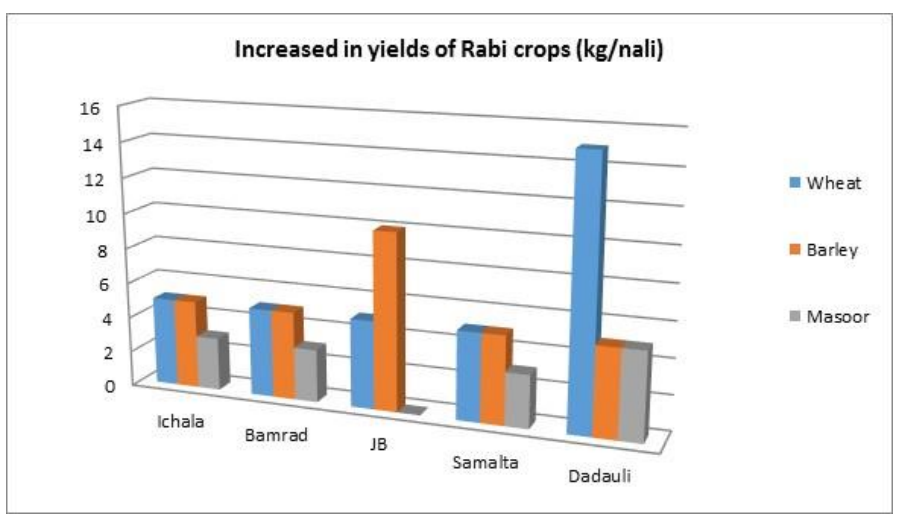

Figure 9. Graph showing the increase in yields of Rabi crops

Livestock in the area has been reduced in terms of cattle units (Fig 12). The reason is that villagers are now using improved techniques, going for more cultivation and reduced paddy husk. More important is attitudinal change towards high yielding varieties (milking cattle). However, people are going for more poultry business, which is used for their own household purposes as food and additional livelihood.

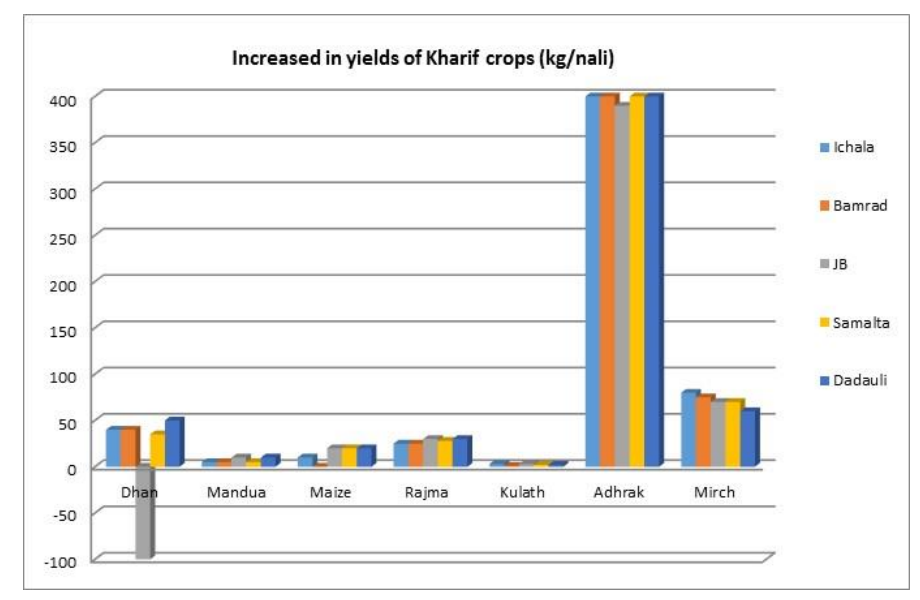

Figure 10. Graph showing the increase in yields of Kharif crops

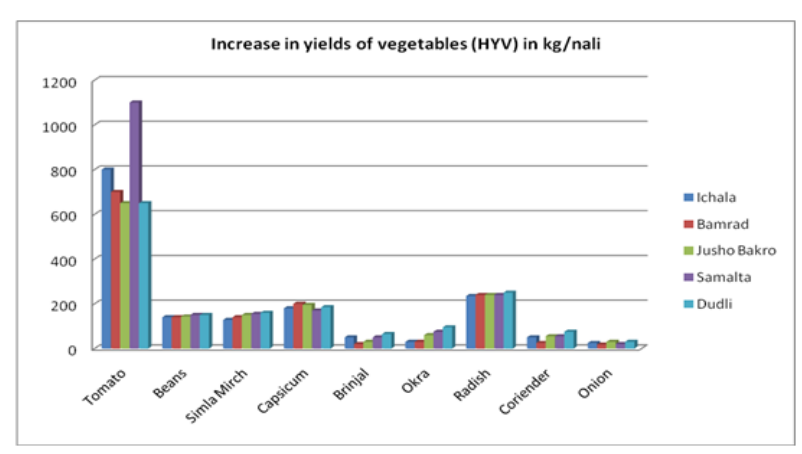

Figure 11. Graph showing the increase of yields of vegetables (HYV)

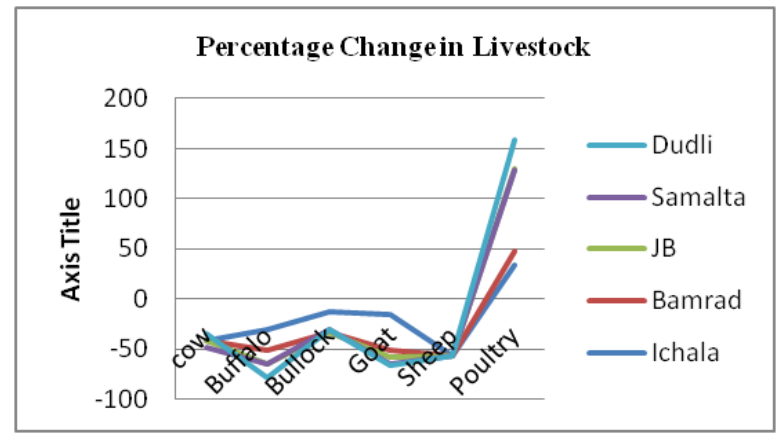

Figure 12. Graph showing the percentage in livestock

Note: 1 Nali $=0.02$ ha. Nali is a local unit area of land prevalent in the study area 
An area of 19.5 ha has been planted with forestry plantations. In addition 940 plants of improved variety of various fruit species such as apple, pear, and apricot have been planted in the area. These plants have survival rate of around $70 \%$. A nursery for raising the plants was established in the project area. Soil preparation and seed sowing work were undertaken to raise the plants for upcoming monsoon. There are around 1800 plants available in the nursery at the time of the data collection. Two Forest Protection Committees (FPCs) are engaged in protecting and managing the forest area in the watershed. Regular meetings and trainings are conducted where officials from Forest Department are also invited so as to strengthen linkages between FPCs and FD.

\subsection{Impact on households}

At household levels, technique has changed from chemical to organic manure, which is environmentally sustainable. Impact at household level can be seen in terms of the introduction of vegetables that yield them more returns in a shorter crop rotation. This has enhanced labour and livelihood opportunity in the project area.

Due to the introduction of solar lighting systems as solar lanterns or solar home lighting system or both in each house of all the villages in the watershed project area (Fig 13), living standard in each household has increased while reducing the expenditure in fuel energy. This is contributing in the better management of the non-renewable energy by reducing the use of kerosene for home lighting since this has already been replaced by the use of solar appliances.

All the houses in the villages have been introduced with improved chulhas replacing the traditional low efficient and environmentally hazardous chulhas that have been in use in the households for the past many decades (Fig 13). Due to this improved cook stoves with chimneys all the kitchens in the entire watershed area are smokeless thus improving both in energy saving mechanism and human health especially that of women and children who are otherwise worse affected. Likewise, people are now more aware about health and hygiene issues including proper waste management. All these changes are consequently improving the quality of life. Towards the end of the project activities, focus has been laid down in strengthening the local level institutions, further building their capacities and linking them to the concerned government departments and other systems of governance for long term sustainability of initiatives undertaken in the project.

Change in the Energy Management

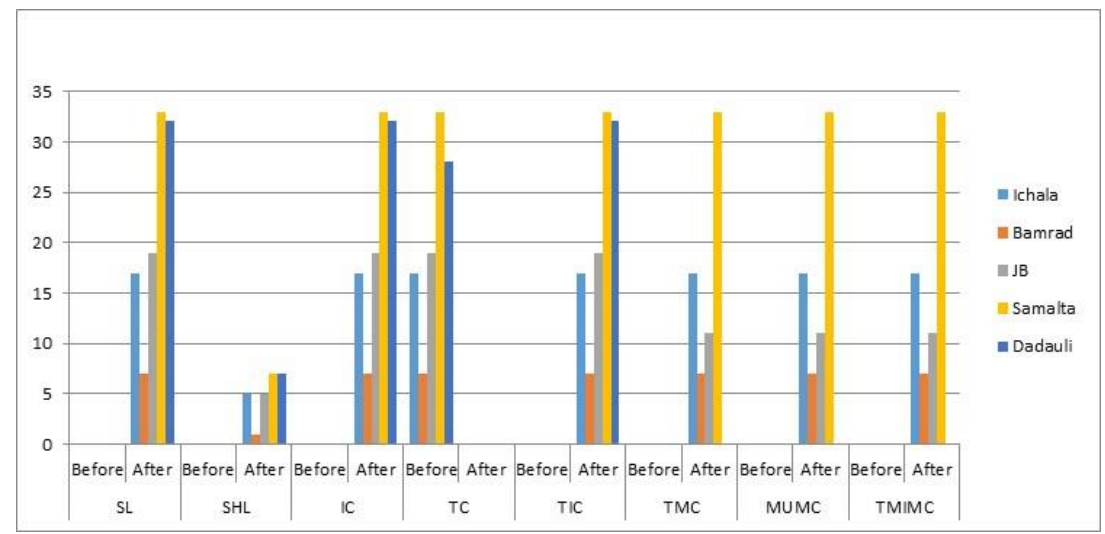

Figure 13. Graph showing the change in the energy management

Note: SL-Solar Lantern, SHL-Solar Home Lighting, IC-Improved Chulhas, TC-Traditional Chulhas, TIC-Traditional \& Improved Chulhas, TMC-Traditional \& Metallic Chulhas, MUMC-Metallic \& Improved mud Chulhas and TMIMC-Traditional Metallic Improved mud Chulhas

There are visible impacts in terms of improved health and sanitation with increasing number of houses with toilets and bathrooms. Cleanliness in households as well as in the villages has become a part of their 
life due to improvement in waste disposal systems and awareness about health and sanitation. People have become aware of the linkage between health and sanitation.

Household level schedule survey indicates that all the villagers wash their hands with water before and after defecation mostly with soap though some people are still using mud for the purpose. Many of the households were motivated to construct bathrooms in their own expenditure. Interactions with the households reveal that more than $50 \%$ of the households are having bathrooms. Each household started using dustbins. Waste disposal system has been improved considerably with mostly closed wastewater disposal system and other waste disposal system. The entire villages appear to be cleaner than before that eventually improve the health and hygiene of the people. Besides, due to hygienic practices and related activities in the schools, there has been a drop in number of cases of children taking leave owing to ill health. Now there are local institutions taking in place, which are shouldering the responsibility of their development. However, sustained efforts need to be made for building the capacities of the local institutions in managing and disseminating the technologies provided through the project and linking them with Gram Panchayats and line government departments for future sustainability of the project.

\subsection{Impact on economy}

Improvement in income, especially of women, has been witnessed in the villages. Additional income generated through the enterprises has given a new confidence to the women of the area. Improvements in household income due enterprises and SHG, especially by women, have resulted in withstanding the impacts and pressures incurred in. All the activities such as poultry production, aromatic plants and vegetable cultivation, paper plate making and mushroom cultivation had a significant impact on quality of life of the community and especially on women in terms of change in income. Improvement in financial conditions had strengthened their position in decision-making in family matters. Income from these micro enterprises has supplemented their income from agricultural activities. Due to their participation in Self Help Groups (SHGs) and regular capacity building, they are able to articulate their concerns and opinions. Participating actively in these activities has increased their awareness in group organization, education, technology, marketing, linkages and environment. Training and exposure programmes have further resulted in various improvements at the community level. Though it would take much longer to completely change the socio-economic conditions in the project area, nevertheless, there has been a good progress in this direction during the short span of the project implementation period.

\subsection{Capacity building}

The impact of capacity building and community mobilisation on the project activities has been tremendous. All the activities in the watershed are done through the watershed development committee (WDC) and village development committees (VDCs). This has built the confidence and capacities of the community to take forward such activities. In addition, VDC and WDC have been able to flag development issues relevant to the village and the sub-watershed. Composition of VDC at the village level has provided a platform where development issues relevant to the village can be discussed. Similarly, WDC has been an important institution to knit together the community at the watershed level. The WDC has also provided a platform to discuss inter-village issues. As a part of exit strategy, WDC has started reporting to the gram panchayat. This has ensured greater accountability of the WDC to the panchayat and the larger watershed community. Self Help Groups (SHGs) have made a very positive impact on the women. Women meet at least once a month now and discuss various developmental issues. They have saved significant amounts through their monthly savings (see details above). These groups are lending money to the needy group members on moderate interest rate. So, group members do not need to go to moneylenders who charge exorbitant interest rates. Women are utilising this money for their personal use as well for investing in agriculture and other enterprises. These groups have made women much more confident. Now they have even started raising their concerns in common village meetings. Most of the activities have been completed or are near to completion including an exposure tour for the community members from all villages and a refresher-training programme for SHGs. Regular meetings and discussions continue to take place in the project area. Training programme for SHGs had been organised within. There are continued emphasis on networking village institutions with different government departments and Gram 
Panchayats. There have been undertaken initiatives to ensure sustainability in the area. Hence, to take forward that agenda, a refresher-training programme of VDC, WDC and SHGs has been organised at the micro-watershed level.

\subsection{Bridging technology and science to the community}

TKC (TERI Knowledge Centre) has opened a new dimension to the local people by making them aware about IT, internet facility and related services. The Centre provides services such as DTP, internet browsing and digital photography. Centre has become financially sustainable with an average monthly net income of above Rs. 3500 for the entrepreneur. Efforts are made to establish centre as the heart of various developmental activities. Various agricultural inputs like improved seeds, bio-fertilisers etc. are being sold. Young children in the area and adjoining places are soon to be benefited with computer education through this centre. The local population has gained a number of services from the centre. Apart from reducing the opportunity cost of access to services, the centre is also being seen as a hub of other activities, which are useful to the community. Villagers and Entrepreneur have been benefited from the centre in more than one way. The centre has facilitated the access of following services to different stakeholders such as villagers and entrepreneurs; villagers in terms of access to products and service of need and desire at their doorsteps, availing products and services at par with the urban counterparts, saving of time as well as money, and opportunity cost, community binding, exposure to new ways of leading life, improve quality of life, entertainment, information about various schemes and issues, and entrepreneur in terms ofno need to migrate for opportunity, opportunity to own an enterprise, exiting opportunity to associate with best organizations, an increase in social standing, multi-point service delivery centre for rural areas, and increasing the awareness and educational levels of the rural mass. The Knowledge Centre at Sahiya has been running smoothly and successfully.

According to the NAPCC, the Indian government aims at following development strategies directed to including crop improvements, forestry, drought proofing, water, health, risk and disaster management. Moreover, the enhancing adaptive capacity at different levels includes introducing and/or enhancing governance to climate focus development, mainstreaming climate change into development planning including afforestation, water and irrigation management, women empowerment, livelihood and economic improvements, energy management, institutional and policy reforms (Mirza, 2007), integrated natural resources management including other development planning procedures (UNDP-GEF, 2007), health and sanitation including health education programmes (WHO, 2005) and embracing a sustainable growth and development course (Ganguly K. and Ranjan G., 2010). In the light of the above discussions, it is obvious that the different activities undertaken in the project area which fetched dramatic improvement in various fields of development including ICT (Information Communication Technology) and capacity building besides the above mentioned areas prove to be significant adaptive measures against the ill effects of the changing/varying climate in the area.

\section{Conclusions}

Various interventions made by the Project Implementation Agency (PIA) are found to be effective in improving the water regime and livelihood to the people. Watershed projects improve the land productivity and water regime in the project areas so that it will produce sustainable livelihood to the communities. Vulnerability and issues for development to cope with the changing climate and its severity could be seen from the watershed characterization. Climate change has disturbed the living pattern of the rural community over the past decades. The watershed interventions made in the Jusho Bakro microwatershed could improve and revive some of the natural resources like soil and water though interventions are still in deficit to meet or tackle the effect of climate change on the local livelihood. The increase in the water level and number of water bodies is definitely fetched through the strong community institutions for sustainable and long strategy in withstanding the effects of climate change. It can be seen from the study that watershed development strategy begins with the treatment plans for augmenting natural resources, but does not end there; inclusion of components are enhanced through 
access to credit, new technology and skills to ensure the livelihoods of different sections of the community including farmers, agricultural labourers and women. This aspect is found to be improving gradually in the study area though the actual impact can only be visible after the complete withdrawal of the project from the area.

As a measure for the sustainable management of the resources and a better livelihood options for the rural villagers in the Jusho Bakro micro-watershed, the specific planning designed to overcome the complexity and the severity in addressing the effects of climate change has helped to withstand the severity of the climate change in the area. Therefore, it is seen that watershed development project gives a positive impact in combating the negative effects of climate change on the natural resources and sustainable livelihood of the local people. The impact assessment of the present watershed program has been found to be a better adaptation mechanism that is much suitable to the study area.

\section{References}

Agder N., Agrawala S. and Mirza M. (2007), Assessment of Adaptation Practices, Options, Constraints and Capacity. In:Climate Change 2007: Impacts, Adaptation and Vulnerability: Summary for Policymakers. Working Group II Contribution to the Intergovernmental Panel on Climate Change Fourth Assessment Report. IPCC, Geneva.

Bruce J., Lee H. and Haites E. (1996), Climate Change 1995: Economic and Social Dimensions of Climate Change, IPCC Report, Cambridge University Press, Cambridge.

Burton I. and van Aalst M. (1999), Come hell or high water - integrating climate change vulnerability and adaptation into Bank work. World Bank, Washington D.C., pp. 60.

Huq S., Rahman A.A., Konate M., Sokona Y. and Reid H. (2003), Mainstreaming adaptation to climate change in least developed countries (LDCS). IIED, London, pp. 57.

IPCC (2001), Climate Change 2001: Impacts, Adaptation and Vulnerability. In: Contribution of Working Group II to the Third Assessment Report of the Intergovernmental Panel on Climate Change. Cambridge University Press, Cambridge, U.K.

IPCC (2007), Summary for Policymakers. Contribution of Working Group I to the Fourth Assessment Report of the Intergovernmental Panel on Climate Change. IPCC, Geneva.

Kaushik Ganguly and Gyana Ranjan Panda (2010), Economic Justice - Climate Change: Adaptation to Climate Change in India, In: A Study of Union Budgets, Oxfam India working papers series May 2010 OIWPS - I, Oxfam India.

Lim B., Spanger-Siegfried E., Burton I., Malone E. and Huq S. (2005), Adaptation Policy Frameworks for Climate Change: Developing Strategies, Policies and Measures. Cambridge University Press, New York, pp. 258.

Mirza M. (2007), Climate Change, Adaptation and Adaptative Governance in Water Sector in South Asia, In: Scarborough (Canada): Adaptation and Impacts Research Division (AIRD), Department of Physical and Environmental Sciences, University of Toronto.

Smit B., Burton B., Klein R.J.T. and Wandel J. (2000), An anatomy of adaptation to climate change and variability, Climatic Change, 45, 223-251.

Smithers J. and Smit B. (1997), Human adaptation to climatic variability and change, Global Environmental Change, 7(2), 129-146.

Subbiah Arjunapermal R. (2002), Climate Variability and Information Applications in Southwest Asia. Asian Disaster Preparedness Center. Extreme Climate Events Program.

UNDP-GEF (2007).Climate change impacts, vulnerability and adaptation in Asia and the Pacific, In: A background note for the Training Workshop on Environmental Finance and GEF Portfolio Management, 22-25 May 2007, Bangkok, Thailand.

WHO (2005),Human health impacts from climate variability and climate change in the Hindu Kush- Himalaya region, In: Report from an Inter-Regional Workshop, Mukteshwar, India, October 2005. 